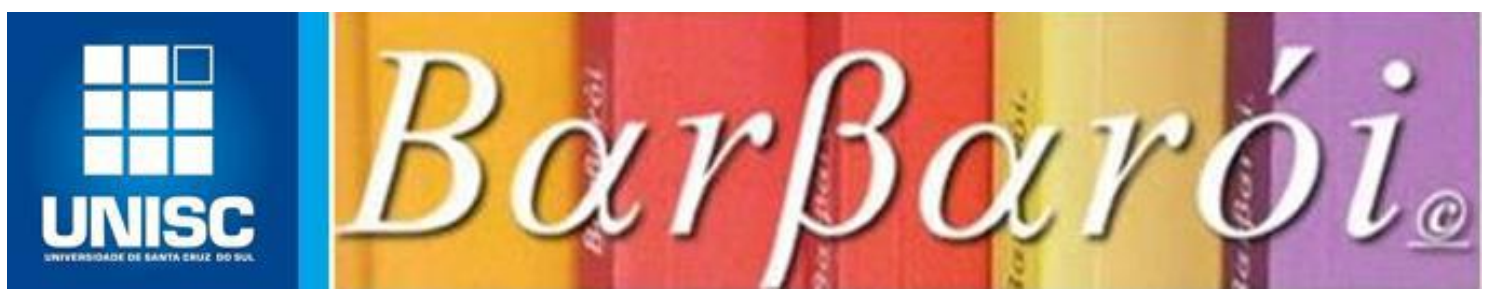

\title{
A RESSONÂNCIA DOS MANUSCRITOS HINDUS E CHINESES NA DOUTRINA DE ARTHUR SCHOPENHAUER
}

\author{
DOI: http://dx.doi.org/10.17058/barbaroi.v0i0.14591

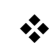

Rosana Jardim Candeloro

Universidade de Santa Cruz do Sul-UNISC - Brasil

$*$

\section{Resumo}

Este artigo pretende inventariar algumas leituras realizadas por Arthur Schopenhauer, na Alemanha do século XIX, e legitimar as ressonâncias de manuscritos da Índia e da China em sua filosofia. Em 1811, Schopenhauer era estudante na Universidade de Göttingen e nesse período o contato íntimo com informações sobre a Ásia o transformaram num entusiasta pelo misticismo chinês e hindu. Em 1813, tomou conhecimento das sabedorias hindu e chinesa, através de revistas especializadas (Asiastisches Magazin/Asiatic Researches), que estavam disponíveis na biblioteca que frequentava regularmente, uma instituição privada pertencente à Duquesa Anna Amália (Herzogin Anna Amalia Bibliotek), em Weimar. Após anos de estudo, é possível perscrutar, na primeira edição de $O$ Mundo como vontade e representação (19181919), os resultados desse empreendimento acadêmico. Para este artigo, buscou-se estabelecer as ressonâncias em obras tardias do filosófico, a saber, o ensaio "Algumas observações sobre a literatura sânscrita", do volume II de Parerga e Paralipomena (1851), e o capítulo de Sobre a vontade da natureza intitulado "Sinologia", extraído da segunda edição de 1854.

Palavras-chave: Asiastisches Magazin. Asiatic Researches. Oupnek'hat. Sinologia. Literatura Sânscrita.

\section{Introdução}

Na efeméride dos 200 anos de publicação de $O$ mundo como vontade e representação (Die Welt als Wille und Vorstellung), celebrada em 2019, ainda pouco se avançou em relação às evidências das ressonâncias que a doutrina schopenhauriana deslinda, considerando as leituras realizadas por Arthur Schopenhauer de manuscritos das sabedorias chinesa e hindu, que grassaram no período de pós-doutoramento até o final de sua vida intelectual.

Este artigo tem como objetivo inventariar e localizar os elementos provenientes de textos antigos da Índia e da China, que foram estudados por Schopenhauer, ao longo de 
muitos anos, e que ressoaram em seus textos, especificamente, no ensaio "Algumas observações sobre a literatura sânscrita" ("Einiges zur Sanskritlitteratur"), publicado no volume II de Parerga e Paralipomena (Parerga und Paralipomena), e do capítulo "Sinologia" ("Sinologie"), inserido na obra Sobre a vontade na natureza (Über den Willen in der Natur), em sua segunda edição, de 1854.

Localizadas as ressonâncias de textos hindus e chineses no corpus filosófico schopenhaueriano, eleito especificamente para este artigo, proceder-se-á aos devidos comentários dos textos selecionados.

A seguir, iniciaremos pela tradição hindu a partir da qual já é possível verificar o quanto Schopenhauer a valorizava, bem como a contribuição efetiva que versos e comentários de tradutores forneceram ao constructo de sua metafísica.

\section{A penetração da espiritualidade hindu na doutrina schopenhaueriana}

Urs App ${ }^{1}$ sinaliza que o texto hindu favorito de Schopenhauer, traduzido por AnquetilDuperron $^{2}$, obra na qual compilou 50 das Upanishad, era o Oupnek'hat ${ }^{3}$. No ensaio "Algumas observações sobre a literatura sânscrita", do volume II de Parerga e Paralipomena, o filósofo revela a forte impressão que o Oupnek'hat deixou em seu ser: “[...] como sopra o espírito sagrado dos Vedas através do Oupnek'hat! [...] é a leitura mais gratificante e comovente que possa haver neste mundo [...]; ela tem sido o consolo de minha vida e será de minha morte" (SCHOPENHAUER, 2016, p. 117-119).

Não há evidências de que Schopenhauer tenha praticado algum tipo de meditação. A prática meditativa, ortodoxa ou heterodoxa, nem sempre é uma consequência natural para aqueles que investem em pesquisas sobre a espiritualidade hindu. Stephen Batchelor ${ }^{4}$ (1994 apud APP, 2010) critica Schopenhauer por ter preferido ouvir música erudita a meditar. Em Il mio Oriente, um pastiche de textos de Schopenhauer publicado na Itália, cujo posfácio é

\footnotetext{
${ }^{1}$ Urs App é um estudioso suíço nascido em 1949. Formou-se na Alemanha, em Freiburg, mas foi na Temple University, na Filadélfia (EUA), que obteve o título de doutor em Estudos das Religiões, especificamente, na área do Budismo Chinês. Em 2012, foi laureado com o 'Book Prize' pela obra The Birth of Orientalism, publicada pela Editora da Universidade da Pennsylvania Atualmente, aos 70 anos, dedica-se à pesquisa do Zen Budismo, em especial.

2 Abrahan-Hyacinthe Anquetil-Duperron (1731-1805) foi um linguista francês, que dominava o Hebraico, o Persa e o Árabe. Traduziu, pela primeira vez no Ocidente, o Avesta, escritura zoroástrica.

${ }^{3}$ O Oupnek'hat é um manuscrito traduzido do Persa para o Latim por Anquetil-Duperron. Publicada entre 1801 e 1802, Schopenhauer teve acesso a essa tradução, que trazia uma compilação de 50 versos das Upanishad (optouse por não utilizar o plural deste título), texto sagrado hindu datado de mais de três mil e quinhentos anos. $\mathrm{O}$ número total de versos das Upanishad é controverso: a tradição afirma que são 108, mas outras fontes atestam um número maior. Encontram-se imprecisões nas fontes de pesquisa e não raras vezes o próprio Schopenhauer teria cometido equívocos ao fazer alusão a manuscritos da Índia (BIANCHINI; REYDSON, 2012).

${ }^{4}$ Stephen Batchelor é um acadêmico britânico nascido em Dundee, na Escócia, em 1953. Fez práticas de Zen Budismo na Coreia do Sul, possui publicações sobre esse tema e é um estudioso da secularização do Budismo.
} Barbarói, Santa Cruz do Sul, Edição Especial n.54, p.<34-46>,jul./dez. 2019 
assinado por Giovanni Gurisatti ${ }^{5}$ (2007), acompanhamos sua argumentação que também indica a falta de interesse de Schopenhauer pela prática meditativa e enfatiza que seu "nirvana" teria mantido somente um teor especulativo. Estudiosos da obra do eminente alemão estão de acordo que foi ele o primeiro filósofo ocidental a tratar a sabedoria asiática de modo profundo e que há, efetivamente, uma concordância entre os escritos de Buddha e a doutrina de Schopenhauer. Segundo App (2010), ele foi pioneiro na descoberta de manuscritos orientais no século XIX.

Mesquita recorre à lembrança de que:

[...] o pensamento oriental foi, em grande parte, desvalorizado pela academia e filosofia do Ocidente, salvo raras exceções. Por isso, analisamos a importância e o significado da voz "secreta" e "surda" que Schopenhauer fez questão de comparar e enaltecer com o seu sistema de pensamento (2007, p. 12).

Em 1813, Schopenhauer doutorou-se em Filosofia pela Universidade de Berlim com a tese Sobre a raiz quádrupla do princípio de razão suficiente. Em dezembro deste mesmo ano, já estava de volta à casa de sua mãe Johanna Schopenhauer, que se estabelecera em Weimar nessa época. No inverno de 1813-1814, Schopenhauer foi apresentado por sua mãe a um discípulo de Herder, o professor Friedrich Majer ${ }^{6}$ (SAFRANSKI, 2011), contato que o impressionou e, talvez, disso tenha decorrido sua visita a Ducal Library, em Weimar, da qual retirou dois volumes da coleção Asiatisches Magazin (Asiatic Researches) e não os devolveu até o final de março de 1814, conforme visitas in loco de vários pesquisadores. O editor dessa revista era Julius Heinrich Klaprot ${ }^{7}$, um orientalista renomado nos meios eruditos, que esteve nessa cidade por dois meses, exatamente no mesmo período em que Schopenhauer, então com 25 anos, frequentava a biblioteca. App (2010) considera que Klaproth poderia ter relação com a indicação pontual de tais volumes, posto que estava envolvido em uma pesquisa que muito interessou a Goethe, também residente em Weimar, à época.

Entre 1815 e 1816, Schopenhauer mergulhou profundamente no estudo de artigos da coleção das Asiatic Researches - revistas sobre os mais variados temas orientais -, antes de iniciar a redação de sua obra fundamental, em 1817, O mundo como vontade e representação. Por conseguinte, utilizou-se de alguns dados dessas leituras para fundamentar seus argumentos de $O$ Mundo... (APP, 2010).

\footnotetext{
${ }^{5}$ Professor de Filosofia da Universidade de Pádova, Itália.

${ }_{7}^{6}$ Orientalista germânico (1772-1818) e notável especialista nos temas hinduístas.

7 Julius H. Klaproth (1783-1835) nasceu em Berlim, na Alemanha. Atuou como linguista, historiador e etnógrafo, além de orientalista. Dominava como poucos as línguas do Cáucaso. Sua grande obra é intitulada Asia Polyglotta, de 1823.
}

Barbarói, Santa Cruz do Sul, Edição Especial n.54, p.<34-46>,jul./dez. 2019 
Nos tempos de Dresden, Schopenhauer teve um vizinho, Karl Christian Friedrich Krause, também filósofo, mas que, diferentemente do primeiro, dominava o Sânscrito. Emprestou a Arthur inúmeros livros de sua biblioteca particular, além de suas próprias traduções de manuscritos da Índia (SAFRANSKI, 2011).

Apaixonado pela literatura sânscrita, Friedrich Schlegel foi também responsável pela elevação que Schopenhauer vai proporcionar, na Alemanha, aos escritos da Índia:

\begin{abstract}
Schopenhauer tem seus primeiros contatos com a cultura oriental ainda em sua juventude, a partir da moda oriental que se impregnou na Alemanha no século XIX. Grande parte dessa forma de pensar se origina na tese do filósofo romântico Friedrich Schlegel (1772-1829), de que uma considerável parte do ocidente teria se originado no oriente, fazendo assim um efervescente renascimento oriental entre os alemães. Foi um reencontro de um tesouro que por muito tempo ficou desconhecido (grifo do autor. REDYSON, 2010, p. 2).
\end{abstract}

Conforme a visão de Helena Blavatsky ${ }^{8}$, a maior parte dos representantes dos ciclos eruditos europeus tratava com descaso a sabedoria da Índia. Em uma de suas obras, encontrase uma passagem que reproduz o lamento de um orientalista germânico, alertando que os Vedas foram escarnecidos e repudiados como uma falsificação moderna (MULLER ${ }^{9}$ apud BLAVATSKY, 1991).

Em um determinado momento dos estudos, Schopenhauer deparou-se com traduções de textos primitivos do Budismo, como atesta Ferreira (2007, p. 7):

Será percebida a presença de passagens do Dhammapada ${ }^{10}$ no decorrer do texto. A escolha desta obra se deu pela importância de seu conteúdo em termos dos ensinamentos morais búdicos. Tais versos remetem ao "cânone budista", em língua páli, que manteve, enquanto possível, maior fidelidade para com o budismo primitivo.

A ressonância proveniente da leitura desses manuscritos será fundamental para afiançar o conceito de sua ética como a 'ética da compaixão', apresentada, em 1819, no Livro IV de $O$ mundo como vontade e representação (FERREIRA, 2007).

No ensaio "Algumas observações sobre a literatura sânscrita", do Parerga..., Schopenhauer comenta, no início do parágrafo 185, as leituras realizadas dos Vedas ${ }^{11}$, como a

\footnotetext{
8 A russa Helena Petrovna Blavatsky (1831-1891), conhecida como Madame Blavatsky, foi ocultista e é considerada a responsável pela sistematização da moderna Teosofia.

${ }^{9}$ Friedrich Max Müller (1823-1900) foi também filólogo. Sua obra de envergadura é Sacred Books of the East (51 v.).

${ }^{10}$ O Dammapada é uma antologia de natureza ética que contém 423 aforismos em versos, na língua páli (derivada do sânscrito), na qual foram, originariamente, escritos os cânones do Budismo primitivo.

${ }^{11}$ Os Vedas, livros do conhecimento hindu, formam um conjunto de quatro volumes escritos em Sânscrito védico, do qual se originou o Sânscrito clássico. Há muitas dúvidas sobre o período em que os Vedas teriam sido compostos. De acordo com a fixação linguística da obra, atestava-se que em 1500 a.C., aproximadamente. Todavia, considerando que os Vedas representam a mais antiga escritura da tradição indo-europeia, há uma corrente de pesquisadores que alude sua origem em 2000 a.C. ou antes. Não se pode atribuir um autor humano Barbarói, Santa Cruz do Sul, Edição Especial n.54, p.<34-46>, jul./dez. 2019
} 
“Samhita", do Rigveda", e o Sama Veda 13: "Embora a Samhita dos Vedas não possa ser dos mesmos autores da mesma época que as Upanishad, disso nos convencemos plenamente quando lemos o primeiro livro da Samhita do Rigveda traduzida por Rosen ${ }^{14}$ e do Sama Veda, por Stevenson" ${ }^{15 "}$ (SCHOPENHAUER, 2006, p. 121). Depreende-se dessa citação que Schopenhauer tinha conhecimento de que os livros dos Vedas eram de períodos históricos distintos, posto que as Upanishad são parte do Advaita Vedanta, que, etimologicamente, tem o sentido de "final dos Vedas", "último livro dos Vedas". Portanto, é possível ler o Advaita Vedanta - manuscrito que trata da essência divina, alma ou sopro vital (Atman ou Atma) e da realidade suprema do universo (Brahman ou Brahma). -, antes dos livros dos hinos ou mesmo separado deles.

Mais adiante, no ensaio do Parerga..., o filósofo alemão apresenta uma compreensão interessante da repercussão dos livros dos Vedas:

[...] As Upanishad são, como já se disse, o produto da suprema sabedoria humana e também estão destinadas com exclusividade aos sábios brâmanes; por isso, Anquetil traduz a Upanishad como secretum tegendum ${ }^{16}$. Em contrapartida, a Samhita é exotérica; é para o povo, embora indiretamente, já que contém a liturgia, isto é, as orações públicas e os rituais das oferendas; em consequência, a Samhita oferece uma leitura de todo insípida, a julgar pelas provas mencionadas [...] (grifo do autor. SCHOPENHAUER, 2006, p. 123).

Para Schopenhauer, o Advaita Vedanta (representado aqui pela obra traduzida por Anquetil- Duperron, intitulada Oupnekhat) tinha um caráter esotérico, ao passo que os livros de hinos litúrgicos, um caráter exotérico.

para os Vedas, dado o seu caráter de revelação divina. Assim, a transcendência que emana dos Vedas é chamado de Shruti, ou seja, o que foi ouvido (ZIMMER, 1986).

12 O Rigveda ou Rig Veda é o primeiro volume dos Vedas e é considerado pela tradição como o mais antigo texto do sistema de escrituras sagradas de matriz indo-europeia. É composto de 1028 hinos em louvor aos deuses, organizados em dez livros, chamados de mandalas. 'Samhita' é a seção mântrica dos Vedas (ao contrário da seção brâmana, que possui comentários em prosa. As Upanishad fazem parte desse segundo segmento) inserida no Rigveda, que consiste em orações em forma de hinos metrificados compostos na região do Punjab entre 1700 a.C. e 1100 a. C.

${ }^{13}$ O Sama Veda ou Samaveda é o terceiro livro dos Vedas. Em termos de relevância litúrgica, ele é o segundo mais venerado, depois do Rigveda. Esse volume é composto por hinos através de 1875 mantras, escritos em versos, mas muitos deles são variações do Rigveda, o primeiro livro dos Vedas.

${ }^{14}$ Friedrich August Rosen (1805-1837) nasceu na Alemanha, ministrou aulas na Universidade de Londres e tornou-se membro da Royal Asiatic Society em 1831. Sua primeira tradução do Rigveda apareceu, postumamente, em 1938. Entretanto, é Max Müller, orientalista alemão que viveu a maior parte de sua vida na Grã-Bretanha, um dos mais celebrados tradutores do Rigveda. Em 1868, tornou-se o primeiro docente de Filologia Comparada da Universidade de Oxford, Inglaterra. Antes disso, em 1844, ainda em Berlim, começou a traduzir as Upanishad para Friedrich Schelling, então seu professor. Müller estudou Sânscrito em Paris sob a orientação de Eugène Bournouf e passou a traduzir o Rigveda encorajado pelo mestre. Procurou no primeiro livro dos Vedas a chave para a compreensão das religiões pagãs europeias.

${ }^{15}$ John Stevenson (1798-1858) foi um missionário escocês, que atuou em Bombain, Índia, de 1823 a 1834. Tornou-se um proeminente orientalista e etnógrafo, sendo um dos primeiros tradutores dos Vedas.

${ }^{16}$ A expressão latina tem o sentido de "o segredo que deve ser ocultado".

Barbarói, Santa Cruz do Sul, Edição Especial n.54, p.<34-46>, jul./dez. 2019 
Na sequência, encontra-se uma passagem muito interessante, já no páragrafo 187 do ensaio supracitado. Schopenhauer faz uma crítica ao falso dualismo entre Prakriti e Purusha, elementos constituintes do sistema Samkhya ${ }^{17}$, neste tom:

[...] vemos que toda a filosofia arruinou-se através de uma falsa ideia fundamental: o dualismo absoluto entre Prakriti e Purusha.Todavia, esse é precisamente o ponto em que a escola Samkhya e desvia dos Vedas. - Está claro que Prakriti é a natura naturans $^{18}$. [...] Purusha, no entanto, é o sujeito do conhecimento, pois percebe, é inativo, é um mero espectador. [...] não posso fazer outra coisa senão ver em Prakriti a Vontade e em Purusha, o sujeito do conhecimento (grifo do autor. SCHOPENHAUER, 2006, p. 125-127).

Observe-se que Schopenhauer faz uma aproximação dos elementos de sua metafísica, a saber, Vontade e sujeito do conhecimento, com os conceitos do sistema Samhkya, Prakriti e Purusha.

O filósofo alemão encerra o parágrafo criticando o pedantismo da escola do Shamkhya, posto que a enumeração, significado etimológico do nome da doutrina, e o fato de o sistema enumerar e querer contar as qualidades dos elementos, sinaliza uma estreiteza de visão que pareceu a ele, em sua época, ser um costume da Índia, já que nos escritos primitivos de Buddha ocorria o mesmo, segundo sua compreensão.

Schopenhauer não foi somente um entusiasta dos manuscritos antigos da Índia, mas também teve acesso ao pensamento chinês quando ainda era estudante, conforme constatamos anteriormente. Na sequência, veremos como se deu o enamoramento do filósofo alemão pelos textos da sabedoria chinesa.

\section{Um affair entre o pensamento de Schopenhauer e a sabedoria chinesa}

Em primeiro lugar, é importante enfatizar que duas doutrinas tiveram a ambição de se constituírem como ortodoxias na China, segundo Granet (1997): a corrente chamada Taoísta e a que reivindica a autoridade de Confúcio. Schopenhauer teve acesso à leitura de manuscritos de ambas as tradições chinesas. O estudo sistemático das fontes chinesas, no segmento acadêmico, foi trazida a lume por uma publicação de Urs App - sob a denominação de "SinoPlatonic Papers", do Departamento de Estudos Asiáticos da Universidade da Pennsylvania -,

\footnotetext{
17 Conforme Zimmer (1986), o universo está assentado em uma dicotomia composta de "mônadas vitais", o Purusha, e a "matéria inanimada", chamada de Prakriti. Cada uma das mônadas vitais está associada à matéria cármica e, consequentemente ao Samsara ou à roda das transmigrações de almas. O Samkhya é uma filosofia pré-védica, que fundamenta as bases doutrinais do Yoga e da prática da Ayurveda, e tem como objetivo o cessamento da dor e do sofrimento, através de um estado denominado de "Moksha". Algumas ideias arcaicas do Samkhya podem ser encontradas nos textos védicos, inclusive no Rigveda. Kapila, que viveu antes de Buddha, é considerado o sistematizador do Samkhya, compêndia de tetos de natureza especulativa. Não se sabe quase nada sobre Kapila e seus dados históricos são contraditórios.

${ }^{18}$ É a Natureza criadora, segundo Spinoza.
}

Barbarói, Santa Cruz do Sul, Edição Especial n.54, p.<34-46>, jul./dez. 2019 
intitulada Arthur Schopenhauer and China: A Sino-Platonic Love Affair, de 2010, por ocasião dos 150 anos de morte do filósofo alemão.

Segundo App (2010), Schopenhauer acessou a obra Tao-te-king (Daodejing, O livro do caminho e da virtude), de Lao-tsé (ou Laozi), pela primeira vez, em uma versão de Stanislas Julien $^{19}$, um sinológo francês do Collège de France, de Paris. Seu despertar pela sabedoria chinesa iniciou-se na Universidade de Göttingen, em 1811, em seus dias de acadêmico do curso de Medicina, quando frequentou a disciplina de 'Etnografia' com Arnold Hermann Ludwig Heeren ${ }^{20}$, um historiador especialista em assuntos da Índia. As anotações de Schopenhauer realizadas em sala de aula, transcritas em blocos, foram compiladas e analisadas por App, traduzindo-as, pela primeira vez, da língua alemã para a língua inglesa. Essas anotações, segundo App (2010), não representam os interesses particulares de Schopenhauer sobre o tema, uma vez que são registros de dados de embaixadas, de informações geográficas sobre as províncias da China, além de relatos de jesuítas, que conviveram com os chineses etc.

O primeiro contato do filósofo alemão com o Budismo chinês, chamado na China de Fo ou Religião de Fo (Buddha), deu-se através da leitura do primeiro volume da coleção Asiatisches Magazin (Asiatic Researches), como já vimos acima, retirado da biblioteca via empréstimo. Essas laeituras, marcadas pelo cânone budista chinês, o levaram até o manuscrito "Ensino do Vazio". App (2010) comenta que, logo após o desfrute dos textos chineses, o interesse de Schopenhauer pela Índia estava explodindo. Portanto, ficou claro que o filósofo alemão protagonizou seus estudos de modo independente a partir de 1813 , quando retirou as revistas da biblioteca, e que seu interesse se iniciou pela China e, num segundo momento, pela Índia.

No ensaio "Sinologia", do livro já comentdo anteriormente, Schopenhauer faz uma alusão interessante à população da China, estimada em 367 milhões de habitantes, no segundo quartel do século XIX. Comenta, então: [...] "a civilização avança, geralmente, no mesmo ritmo que a população" (2013, p. 194). Na sequência, constata um imbricamento entre elementos do Taoísmo e do Budismo chinês. Sobre o Budismo chinês, destaca-o como a mais nobre religião do mundo. Por fim, conclui que as doutrinas do Taoísmo, de Confúcio (ou Kongzi) e do Budismo chinês concordam e seriam, num tom proverbial, "apenas uma" (grifo do autor. SCHOPENHAUER, 2013, p. 198).

\footnotetext{
${ }^{19}$ Stanislas Julien nasceu em Orléans, França, em 1797, e faleceu em 1873. Possuía a Cátedra de Chinês no Collège de France.

${ }^{20}$ Arnold Hermann Ludwig Heeren nasceu em Arbergen, Alemanha, em 1760, e faleceu em Göttingen, em 1842. Foi historiador e professor da Universidade de Göttingen, Alemanha.
}

Barbarói, Santa Cruz do Sul, Edição Especial n.54, p.<34-46>, jul./dez. 2019 
Abaixo, desvela-se como o pensamento chinês reverberou nos círculos acadêmicos europeus, no século XIX, e qual foi o índice de adesão dos signatários da Filosofia alemã à sabedoria chinesa.

\subsection{O pensamento asiático e sua recepção entre os expoentes da Filosofia Moderna}

Florentino Neto (2015) divide as influências do mundo oriental sobre a produção filosófica ocidental em duas clivagens: positivas e negativas. Com Leibniz e Wolff, há um acolhimento e uma interpretação positiva do pensamento chinês. A recepção negativa do diálogo com essa vertente foi capitaneada por Herder, Hegel e Schelling. Segundo o autor, essas ideias repercutem no meio acadêmico até os dias atuais.

A ruptura do Japão com o mundo ocidental e a proibição do cristianismo em solo japonês, até 1860, promoveram uma migração do potencial evangelizador dos missionários, especialmente dos jesuítas, para a China. Com isso, um processo de intercâmbio inicia-se entre o pensamento chinês e o Ocidente.

$\mathrm{Na}$ visão do autor, conviviam, simultaneamente, duas posições de parte da Igreja Católica quanto à evangelização dos chineses: uma delas considerava a cultura chinesa fortemente hidratada pelo ateísmo, o que dificultava a justificação da existência de Deus e a doutrinação cristã. Outra parte admitia a compatibilidade entre a cultura, os ritos chineses e a cristianização. Esse certame foi batizado pelos intelectuais da época de "a querela dos rituais" (FLORENTINO NETO, 2015). Os primeiros escritos filosóficos da modernidade sobre o pensamento chinês são forjados nesse contexto.

Na esteira da Filosofia da História de Hegel, de 1837, conforme Santos (2016) e Florentino Neto (2015), o pensamento filosófico tem seus primórdios na Grécia e somente no mundo ocidental emergeria a liberdade da autoconsciência. Qualquer outro pensamento, procedentes de países do Oriente, estaria fora da análise empreendida por Hegel.

Santos (2016, p. 138) resgata os pressuspostos de Hegel, em um trecho de seu artigo: "Os orientais (chineses, egípcios, hindus) [...] não têm ainda o conhecimento da liberdade como essência do mundo humano. E, dessa ignorância, surge a impossibilidade de concretizála $[\ldots] "$.

Florentino Neto (2015, p. 11) relativiza, entretanto, as considerações de Hegel:

algumas de suas afirmações sobre a liberdade do homem, especialmente no que diz respeito aos chineses, não podem ser totalmente aceitas. Do fato de o homem livre, como condição para o surgimento da filosofia europeia, representar um aspecto importante de seu pensamento não se segue, necessariamente, que em outro lugar não tenha havido homem livre, ou que a filosofia não tenha tido lá outras referências iniciais.

Barbarói, Santa Cruz do Sul, Edição Especial n.54, p.<34-46>, jul./dez. 2019 
A vertente negativa da percepção do pensamento oriental, entre alguns filósofos modernos, não se disseminou de modo unânime e não contaminou todas as fontes de criação do pensamento moderno. A seguir, veremos a dimensão da ressonância dos escritos da sabedoria milenar chinesa no pensamento schopenhaueriano.

\subsection{Considerações arqueológicas do ensaio "Sinologia"}

Florentino Neto (2015) não se reporta a Arthur Schopenhauer em seu artigo, não obstante o fato de que há evidências de que o filósofo alemão tinha conhecimento de textos do pensamento chinês.

No período em que Schopenhauer viveu em Frankfurt, no final de sua vida, escreveu um livro tardio intitulado Sobre a vontade na natureza, já referenciado anteriormente. Ele nutria, à época, interesse pela Parapsicologia e desfilava suas verdades metafísicas para ressignificar uma série de constatações científicas dos elementos do mundo natural.

Nesse livro, o ensaio "Sinologia", que está inserido nas duas primeiras edições alemãs do livro supracitado21 (1836 e 1854, respectivamente), Schopenhauer desfia suas explanações, que remontam às pesquisas de eminentes orientalistas do século XIX, a saber, Robert Spence Hardy22 e Isaac Jacob Schmidt23. Seguem, abaixo, comentários do filósofo acerca das três doutrinas chinesas as quais ele já havia desvendado:

[...] Primeiramente, a da Tao-she, fundada por Lao-tse, um contemporâneo mais velho de Confúcio. Trata-se da doutrina da razão enquanto ordem cósmica interna ou princípio íntimo de todas as coisas, o grande um, a antiga viga (Taiki) que carrega todas as telhas do telhado e ainda assim se encontra acima delas (na verdade, a alma cósmica que tudo penetra), e do Tao, quer dizer, do caminho, aquele para a salvação, isto é, para a redenção do mundo e de suas misérias. Uma apresentação dessa doutrina a partir de sua fonte nos foi fornecida por Stanislas Julien no ano de 1842 na tradução do Tao-[te]king de Lao-tse: vemos, a partir daí, que o sentido e o espírito da doutrina taoísta concordam completamente com o budismo (SCHOPENHAUER, 2013, p. 195 - grifos do autor).

\footnotetext{
${ }^{21}$ Usou-se como base, para este artigo, o ensaio publicado na segunda edição, de 1854.

22 Robert Hardy Spencer (1803-1868) publicou On Eastern Monachism, em 1860. Todas as suas publicações podem ser acessadas na Hathi Trust Digital Library, em: http://www.babel.hathitrust.org.

${ }^{23}$ Isaac Jacob Schmidt (1779-1847) nasceu em Amsterdã, Países Baixos, mas passou uma parte de sua vida trabalhando na Rússia como missionário e dedicando-se sobremaneira à tradução da Bíblia. Foi um orientalista especialista em textos tibetanos e mongólicos.
}

Barbarói, Santa Cruz do Sul, Edição Especial n.54, p.<34-46>,jul./dez. 2019 
No Taoísmo não há propriamente a ideia de criação (GRANET, 1997). A cosmovisão taoísta é não essencialista e corporificada na experiência individual e coletiva, em um mundo em constante mutação (BIZERRIL NETO, 2005).

No compasso de sua abordagem, o filósofo alemão revela o Confucionismo:

[...] Em segundo lugar, encontramos a sabedoria de Confúcio, à qual se dedicam especialmente os doutos e homens de Estado: a julgar pelas traduções, trata-se de uma filosofia abrangente, baseada em lugar-comum, preponderantemente moral e sem metafísica para apoiá-la, e que tem em si algo de especificamente insípido e tedioso [...] (SCHOPENHAUER, 2013, p. 196).

Dando continuidade à sua apresentação das três doutrinas chinesas, Schopenhauer finaliza com o Budismo:

[...] Por fim há, para a grande massa da nação, a antiga e amorosa doutrina de Buda, cujo nome, ou melhor, cujo título é pronunciado na China Fo ou $\mathrm{Fu}$, enquanto o vitoriosamente perfeito é chamado entre os tártaros mais pelo seu nome de família, Sakyamuni, mas também Burkhan-Bakshi entre os birmanenses e, no Ceilão, na maioria das vezes de Gautama, também Tatagata, mas que originalmente, porém, se chama príncipe Siddharta [...] (SCHOPENHAUER, 2013, p. 196 - grifos do autor).

Após uma década de leituras aprofundadas de traduções e artigos, especialmente, de autores como Klaproth, Schopenhauer chega aos anos 1830 continuamente instigado pelo pensamento de origem chinesa. App (2010) atesta que o filósofo alemão demonstra um certo receio de que o acusem de ter retirado o constructo de sua doutrina da vontade diretamente do pensamento chinês. Talvez, esse tenha sido um dos motivos que o levou a conceber o ensaio "Sinologia", em Sobre a vontade na natureza, inserido no final do volume, com a perspectiva de que as ciências empíricas, que povoam os capítulos anteriores, associadas ao próprio pensamento chinês, legitimassem a sua metafísica.

\section{Considerações Finais}

Considerando que Schopenhauer, desde tenra idade, interessou-se pela dinâmica conceitual inscrita nos pressupostos das sabedorias chinesa e hindu, pode-se concluir que sua metafísica da Vontade é tributária às doutrinas do Oriente.

O próprio filósofo alemão admite a concordância entre alguns pressupostos do Advaita Vedanta e dos manuscritos do Taoísmo, por exemplo, como se lê na parte final do ensaio "Sinologia". 
No ensaio "Algumas observações sobre a literatura sânscrita", Schopenhauer faz uma reprimenda aos tradutores dos manuscritos da sabedoria hindu, bem como sinaliza as dificuldades do Chinês e a insuficiência de meios auxiliares para a tradução.

Não obstante o difícil acesso às traduções do Persa, do Sânscrito e do Chinês no século XIX, Schopenhauer foi, de fato, um iniciado na sabedoria do Oriente e, com isso, fomentou a diversidade cultural, aproximou o Ocidente do Oriente e, sobretudo, transformou sua metafísica em uma das doutrinas mais interessantes e originais da História da Filosofia.

\title{
THE RESONANCE OF THE CHINESE AND INDIAN MANUSCRIPTS ON ARTHUR SCHOPENHAUER'S DOCTRINE
}

\begin{abstract}
This paper aims to inventory some reading by Arthur Schopenhauer in the $19^{\text {th }}$ Century in Germany, and to legitimize the resonance of manuscripts from India and China on his Philosophy. In 1811, Schopenhauer was a student at the University of Göttingen and during that period he had a close contact with information about Asia which made him an enthusiast for Chinese and Hindu Misticism. In 1813, he learned of Hindu and Chinese Wisdom through specialized journals (Asiastisches Magazin/Asiatic Researches), which were available at the library that he regularly attended, a private institution belonging to Duchess Anna Amalia (Hergozin Anna Amalia Bibliotek) in Weimar. After years of study, it is possible to scrutinize into the first edition of The World as Will and Representation (1818-1819), the results of that academic venture. For this paper, we sought to establish the resonance in his late works, namely the essay "Some Observations on Sanskrit Literature", v. II of Parerga and Paralipomena (1851 and the chapter on On the Will of Nature entitled "Sinology", extracted from the second edition of 1854.
\end{abstract}

Keywords: Asiastisches Magazin. Asiatic Researches. Oupnek'hat. Sinology. Sanskrit Literature.

\section{REFERÊNCIAS}

APP, Urs. Arthur Schopenhauer and China: A Sino-Platonic Love Affair. Sino-Platonic

Papers, n. 200, Philadelphia (University f Pennsilvania), p. 1-177, apr. 2010.

BIANCHINI, F.; REDYSON, D. A obra Oupnek'hat na filosofia de Schopenhauer. Revista Litterarius, Santa Maria, v. 11, n. 2, p. 157-184. 2012.

BIZERRIL NETO, José. Mestres do Tao: tradição, experiência e etnografia. Horizontes antropológicos, Porto Alegre, v. 11, n. 24, jul./dec, 2005. Disponível em: <http://www. scielo.br>.

BLAVATSKY, H. P. Isis sem véu: uma chave-mestra para os mistérios da Ciência e da Teologia antigas e modernas. São Paulo: Pensamento. 1991. 4v.

CONFÚCIO. Os Analectos. Tradução, comentários e notas de Giorgio Sinedino. São Paulo: Unesp/Instituto Confúcio. 2012. 607 p. 
FERREIRA, Fábio Lustosa. A ética da compaixão de Schopenhauer em sua intersecção com a ética da compaixão budista. Curitiba, PUC/PR, 2007 (dissertação de mestrado). 88p.

FLORENTINO NETO, Antônio. A recepção do pensamento chinês na Filosofia Moderna. $O$ que nos faz pensar, Rio de Janeiro, n. 36, p. 329-341, mar. 2015.

GRANET, Marcel. O pensamento chinês. Tradução de César Benjamin. Rio de Janeiro: Contraponto. 1997.

GURISATTI, Giovanni. Il mio Oriente (compilazione). Milão: Adelphi Edizioni. 2007. p. 187-222 (Piccola Biblioteca Adelphi, 556).

LAO-TSEU. Tao-te-king: Le Livre de la Voie et de la Vertu. Traduction de Stanislas Julien. Paris: Imprimerie Royale. 1842. 296p. (pdf).

MESQUITA, Fábio Luís de Almeida. Schopenhauer e o Oriente. São Paulo, USP, 2007 (Dissertação de Mestrado). 159 p.

SAFRANSKI, Rüdiger. Schopenhauer e os anos mais selvagens da Filosofia: uma biografia. Tradução de William Lagos. São Paulo: Geração Editorial. 2011.

SANTOS, Vinicius dos. A razão realizada? Notas sobre a Filosofia da História de Hegel. Aufklärung, João Pessoa, v. 3, n. 2, p. 127-150, out. 2016. Disponível em: www.redalyc.org. Acesso em: 25 ago. 2019.

SCHOPENHAUER, A. Sinologia. In: Sobre a vontade na natureza. Tradução de Gabriel Valladão Silva. Porto Alegre: L\&PM Editores. 2013. p. 194-207.

Seis ensaios de Parerga e Paralipomena. Tradução de Rosana Jardim Candeloro. Edição bilíngue, Porto Alegre: Zouk Editora. 2016. 182p.

Algumas observações sobre a literatura sânscrita. In: SCHOPENHAUER, A. Seis ensaios de Parerga e Paralipomena. Tradução de Rosana Jardim Candeloro. 2. reimpr. Porto Alegre: Zouk Editora. 2017. p. 113-142.

. Sämtliche Werke. 2a Ausgabe. Wiesbaden: Eberhard Brockhaus Verlag. 1949. 2. Vol. . Parerga y Paralipomena. Traducción, introducción y notas de Pilar López de Santa María. Editorial Trotta: Madrid. 2009. 2 v. (Clásicos de la Cultura).

Parerga y Paralipomena: escritos filosóficos menores. Traducción de Edmundo González Blanco. Málaga: Editorial Ágora. 1997. 3 v. (Coleción Hybris, 13).

REDYSON, Deyve. Schopenhauer e o pensamento oriental: entre o hinduísmo e o budismo. Religare, João Pessoa, v. 1, n. 7, p. 3-16, mar. 2010.

ZIMMER, Heinrich. Filosofias da Índia. Tradução de Nilton Almeida Silva, Cláudia G. Bozza e Adriana F, de Cesare. Organização de Joseph Campbell. 2. ed. São Paulo: Palas Athena. 1986. 510p. 


\section{Sobre a autora:}

Rosana Jardim Candeloro Foi docente de Filosofia no Departamento de Ciências Humanas da Universidade de Santa Cruz do Sul (UNISC), no RS, entre 1992 e 2017. Publicou seu primeiro livro de tradução em 2016, vertendo para o Português seis ensaios de Parerga e Paralipomena, de Arthur Schopenhauer. Endereço Eletrônico: rosanajar-dimc@ gmail.com 